\title{
ENERGOCHŁONNOŚĆ SYSTEMU LOKALNEJ WENTYLACJI MECHANICZNEJ PRZY RÓŻNYCH STRATEGIACH STEROWANIA
}

\begin{abstract}
W pracy przedstawiono możliwości wykorzystania lokalnej wentylacji mechanicznej w pomieszczeniach budynku biurowego przeznaczonych do pracy w ciągu dnia. Zaproponowano różne strategie sterowania jednostkami wentylacyjnymi uwzględniając jakość powietrza w pomieszczeniach w zakładanych okresach użytkowania. Uwzględniono możliwość zasilania centrali w cyklu godzinowym z energii odnawialnej produkowanej na miejscu. Na podstawie uzyskanych wyników energii końcowej stwierdzono, że najkorzystniejszy sposób sterowania polega na ciągłej pracy centrali z najniższym wydatkiem w godzinach 8-16. Jednocześnie jest to wariant charaktertyzujący się najniższą mocą szczytową na ogrzanie powietrza wentylacyjnego przy założeniu częściowego odzysku ciepła (sprawność odzysku 50\%). Porównując energię pomocniczą do napędu wentylatorów najkorzystniejszym wariantem jest przypadek 2 i 3, w którym centrala pracuje przez krótszy czas ale zapewnia większą wymianę powietrza.
\end{abstract}

Słowa kluczowe: wentylacja, sterowanie, budynek biurowy, energooszczędność, jakość powietrza, komfort

\section{Wprowadzenie}

Konieczność zapewnienia zdrowego, przyjaznego mikroklimatu pomieszczeń, w tym jakości powietrza wewnętrznego możliwe jest jedynie dzięki zastosowaniu systemów wentylacji o kontrolowanym wydatku powietrza [1]. Kryteria te spełniają po części systemy wentylacji hybrydowej, zaś w pełni systemy wentylacji mechanicznej. Ich zadaniem jest zapewnienie wymaganego strumienia powietrza w zadanym okresie czasu wynikającym z obecności osób i wymagań higienicznych. Z uwagi na sposób dystrybucji powietrza i możliwości sterowa-

${ }^{1}$ Autor do korespondencji / corresponding author: Małgorzata Szymkowiak, Politechnika Łódzka, Wydział Inżynierii Procesowej i Ochrony Środowiska, ul. Wólczańska 213, 90-924 Łódź; tel. +48 42 631-39-20; 800862@edu.p.lodz.pl

2 Dariusz Heim, Politechnika Łódzka, Wydział Inżynierii Procesowej i Ochrony Środowiska, ul. Wólczańska 213, 90-924 Łódź; tel. +48 42 631-39-20; dariusz.heim@p.lodz.pl 
nia najczęściej spotykanymi rozwiązaniami są systemy centralne lub lokalne [2]. W przypadku systemów centralnych sterowanie odbywa się najczęściej na poziomie budynku natomiast w systemach lokalnych na poziomie poszczególnych pomieszczeń lub wręcz jednostek wentylacyjnych, dając tym samym znacznie większe możliwości oszczędzania energii, zarówno końcowej jak i pomocniczej. Dlatego dla potrzeb niniejszej pracy przyjęto system wentylacji lokalnej z wykorzystanie fasadowych central wentylacyjnych dostarczających powietrze do poszczególnych pomieszczeń. Centrale takie charakteryzują się kompaktowymi wymiarami oraz niewielkim poborem mocy. W przypadku wybranych obiektów, np. budynków biurowych mogą być z powodzeniem zasilane z lokalnie produkowanej (on-site) energii odnawialnej. Sterowanie tego typu urządzeniami odbywa się najczęściej wg profili godzinowych natomiast może być dodatkowo uwarunkowane obecnością użytkowników. Tym samym istnieje spory potencjał do oszczędzania energii bez jednoczesnego pogorszenia jakości środowiska wewnętrznego [3].

Celem podjętej pracy badawczej jest określenie wpływu strategii sterowania działaniem jednostki wentylacji lokalnej zastosowanej w budynku biurowym na łączne zapotrzebowanie na energię. Rozpatruje się energię końcową na potrzeby podgrzania strumienia powietrza wentylacyjnego oraz energię pomocniczą do napędu centrali wentylacyjnej. Analizy przeprowadzono dla przypadku pomieszczenia badawczego zrealizowanego w ramach projektu GPEE, w jednym z budynków Politechniki Łódzkiej [4].

\section{Systemy wentylacji lokalnej}

Systemy wentylacji różnią się między sobą budową, zasadą działania i możliwościami technologicznymi $\mathrm{z}$ uwagi na sposób wymiany powietrza $\mathrm{w}$ pomieszczeniach. Jednym z takich systemów jest wentylacja lokalna. Ten rodzaj wentylacji charakteryzuje się przede wszystkim miejscowym oddziaływaniem i możliwością indywidualnego dostosowania do potrzeb użytkownika danego pomieszczenia. Do tej pory w budynkach biurowych przeważał system wentylacji mechanicznej centralnej, obsługujący kilka bądź kilkanaście pomieszczeń. Jest to system pozwalający tylko minimalnie dostosować się do indywidualnych potrzeb użytkowników. Zaprojektowanie idealnego centralnego systemu wentylacji mechanicznej dla budynków użyteczności publicznej jest zadaniem praktycznie niemożliwym, dlatego w celu spełnienia oczekiwań rynkowych pojawił się szereg rozwiązań dedykowanych dla pojedynczych pomieszczeń.

Zdecentralizowana wentylacja mechaniczna z rekuperacją posiada wszelkie zalety standardowej wentylacji mechanicznej, jednakże jest pozbawiona wielu jej wad. Sprawność systemu odzysku ciepła w tego typu instalacji dochodzi do $90 \%$, co spowodowane jest uniknięciem strat na dystrybucji powietrza w kanałach. Tego typu jednostki nie posiadają typowego wymiennika ciepła, gdyż w tym wypadku strumienie powietrza nawiewanego i wywiewanego nie spoty- 
kają się ze sobą. Na rynku coraz więcej firm proponuje rozwiązania nazywane jednorurowymi systemami wentylacji. System ten zbudowany jest na bazie kanału teleskopowego $\mathrm{z}$ wewnątrz wmontowanym wentylatorem rewersyjnym, ceramicznym wymiennikiem ciepła oraz dwoma filtrami powietrza. Tego typu urządzenia montowane są bezpośrednio $\mathrm{w}$ zewnętrznej ścianie pomieszczenia. Wydajność takich jednostek umożliwia dostarczenie odpowiedniej ilości świeżego powietrza dla dwóch, trzech osób stale przebywających w pomieszczeniu. Drugim rodzajem urządzeń zdecentralizowanych systemów wentylacji są centrale wentylacyjne montowane bezpośrednio w fasadzie budynku. Takie rozwiązanie pozbawia użytkownika konieczności rozprowadzania kanałów wentylacyjnych oraz skraca odległość jaką przebywa powietrze nawiewane do pomieszczenia. Tego typu centrale są urządzeniami nawiewno-wywiewnymi z odzyskiem ciepła. Zastosowanie tego typu systemu lokalnej wentylacji umożliwia indywidualne sterowanie wentylacją w zależności od potrzeb użytkownika, a także ułatwia zastosowanie i zmodernizowanie systemu wentylacji w budynkach istniejących jak i nowobudowanych.

\section{Opis analizowanego przypadku}

\subsection{Charakterystyka pomieszczenia biurowego}

Rozpatrywane pomieszczenie biurowe ma wymiary 4,4 m x 2,6 m x 2,9 m i znajduje się na czwartym piętrze budynku dydaktyczno-biurowego. W pomieszczeniu tym zastosowano fasadę eksperymentalną, $\mathrm{z}$ oknem o wymiarach $1,2 \mathrm{~m} \times 1,2 \mathrm{~m}$. Natomiast podłoga pomieszczenia została wykonana jako podniesiona, zaś w jej przestrzeni zamontowano kompaktową centralę wentylacji fasadowej. Kratka nawiewna i wywiewna znajduje są w podłodze pomieszczenia bezpośrednio pod oknem.

\subsection{Opis urządzenia i sposób działania}

W analizie przyjęto podłogowe urządzenie wentylacji fasadowej typ FSLU-ZAB firmy TROX. Jest to jednostka zdecentralizowanej wentylacji, pracująca $\mathrm{w}$ trybie nawiewno-wywiewnym $\mathrm{z}$ odzyskiem ciepła. Urządzenie składa się z wentylatorów EC o niskim współczynniku mocy właściwej, płytowego wymiennika odzysku ciepła z przepustnicą wyposażoną w siłownik elektryczny, wymiennik ciepła systemu 4-rurowego, filtra klasy F7 na powietrzu zewnętrznym, filtra zgrubnego klasy G3 na powietrzu wyciąganym oraz przepustnic odcinających wyposażonych $\mathrm{w}$ siłownik ze sprężyną zamykającą $\mathrm{w}$ przypadku braku zasilania. Na wyposażeniu znajduje się również specjalnie dostosowany do wentylacji zdecentralizowanej system regulacji X-AIRCONTROL o budowie modułowej. Zastosowanie 4-rurowego wymiennika ciepła umożliwia regulację temperatury powietrza $\mathrm{w}$ pomieszczeniach. 
Jednostka ta przystosowana jest do wentylacji pomieszczeń o głębokości do $6 \mathrm{~m}$ w budynkach nowych i modernizowanych. Dostosowana jest do zabudowy w podłodze podniesionej w pomieszczeniach biurowych, konferencyjnych oraz innych pomieszczeniach z przeszkleniem na całej wysokości kondygnacji. Całe urządzenie ma wymiary: 1100 x 172x $963 \mathrm{~mm}$, dlatego jego zwarta zabudowa jest szczególnie korzystna w obiektach modernizowanych. Dodatkową opcją jest również wyporowy nawiew powietrza do pomieszczeń oraz wykorzystanie zewnętrznego czynnika roboczego do ogrzewania i chłodzenia. Istnieje możliwość regulacji wentylacji zależnie od potrzeb użytkownika, na podstawie monitorowania jakości powietrza w pomieszczeniu. Urządzenie wentylacji fasadowej typu FSL-UZAB może działać w trzech trybach pracy. Tryby te charakteryzują się zadanymi wartościami strumienia objętości powietrza odpowiednio: $90 \mathrm{~m}^{3} / \mathrm{h}, 120 \mathrm{~m}^{3} / \mathrm{h}$ oraz $150 \mathrm{~m}^{3} / \mathrm{h}$. Poziom generowanego przez jednostkę hałasu znajduje się $\mathrm{w}$ przedziale $35 \div 45 \mathrm{~dB}(\mathrm{~A})$. Pobór mocy elektrycznej przy pracy ze zwiększoną wydajnością $150 \mathrm{~m}^{3} / \mathrm{h}$ jest równy $37 \mathrm{~W}$, a przy przepływie nominalnym $90 \mathrm{~m}^{3} / \mathrm{h}$ wynosi $22 \mathrm{~W}$.

Urządzenie zdecentralizowanej wentylacji fasadowej oprócz funkcji nawiewno-wywiewnej odbiera również obciążenie cieplne i chłodnicze z pomieszczenia. Powietrze zewnętrzne jest zasysane przez wentylator promieniowy EC, następnie przepływa przez przepustnicę odcinającą z siłownikiem, regulator przepływu i filtr klasy F7. Kolejnym etapem jest transport powietrza przez wymiennik odzysku ciepła. Wymiennik ten jest w określonych sytuacjach, np. w celu zapobiegania zamarzaniu, wyłączany obejściem otwieranym przepustnicą. Gdy istnieje konieczność powietrze jest dodatkowo chłodzone lub ogrzewane w wymienniku ciepła a następnie nawiewane do pomieszczenia strumieniem wyporowym. Natomiast powietrze wyciągane z pomieszczenia przez wentylator wywiewny przepływa przez filtr G3, wymiennik odzysku ciepła i poprzez przepustnicę odcinającą z siłownikiem jest wywiewane na zewnątrz.

\subsection{Analizowane sposoby sterowania}

Celem podjętej pracy była analiza systemów sterowania zdecentralizowaną jednostką wentylacyjną zainstalowaną w pomieszczeniu badawczym. Podczas analizy brano pod uwagę trzy profile sterowania. Sposób pracy jednostki wg zadanych trzech profili został przedstawiony na rysunkach $1 \div 3$.

Założono, że centrala we wszystkich trzech przypadkach zapewnia wstępne przewietrzanie pomieszczenia, w godzinach $6: 00 \div 6: 30$, pracując $\mathrm{z}$ wydajnością $150 \mathrm{~m}^{3} / \mathrm{h}$. Następnie w pierwszym wariancie następuje ciągła praca jednostki

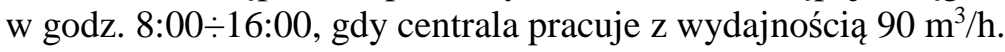

$\mathrm{W}$ drugim wariancie pracy zastosowane zostało cykliczne włączanie i wyłącznie centrali. Na początku mamy wstępne przewietrzanie pomieszczenia w godz. $6: 00 \div 6: 30 \mathrm{z}$ wydajnością $150 \mathrm{~m}^{3} / \mathrm{h}$, następnie urządzenie pracuje

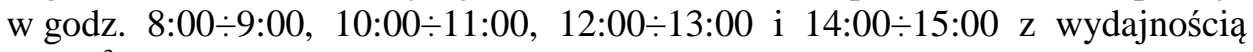
$120 \mathrm{~m}^{3} / \mathrm{h}$. 


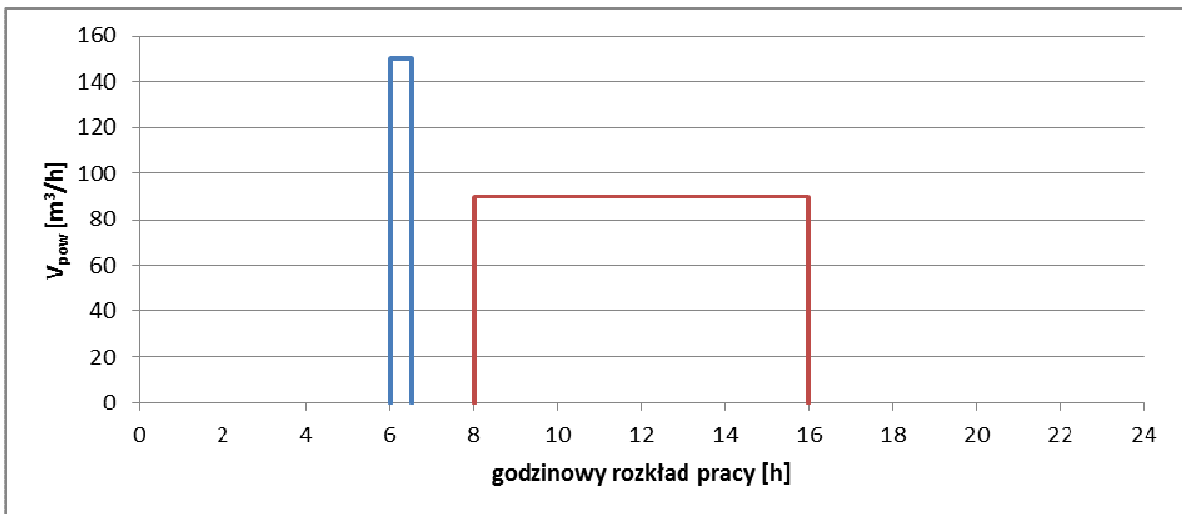

Rys. 1. Profil pracy centrali wentylacyjnej - wariant 1

Fig. 1. The profile of the work of ventilation - option 1

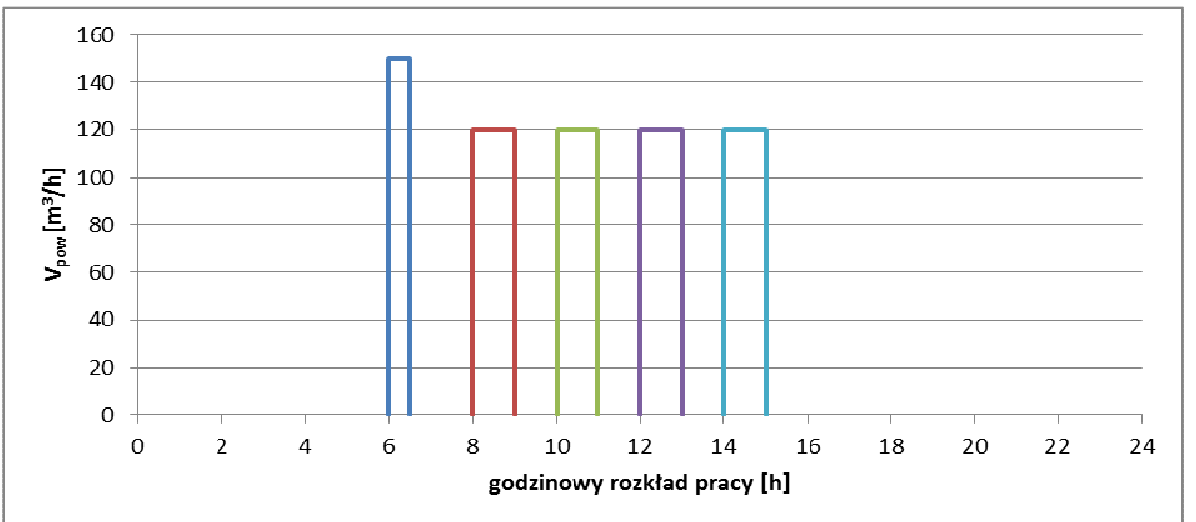

Rys. 2. Profil pracy centrali wentylacyjnej - wariant 2

Fig. 2. The profile of the work of ventilation - option 2

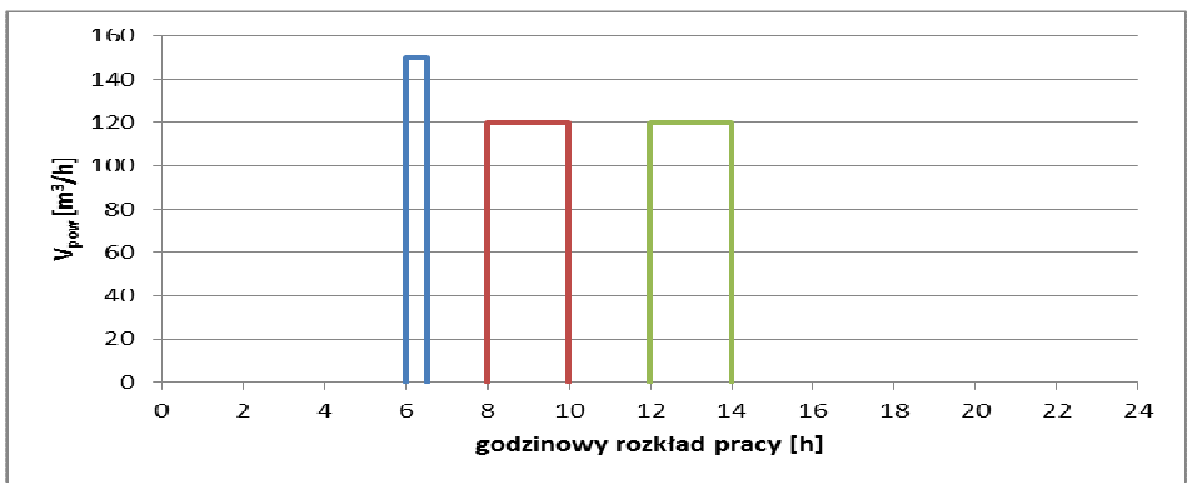

Rys. 3. Profil pracy centrali wentylacyjnej - wariant 3

Fig. 3. The profile of the work of ventilation - option 3 
Ostatni trzeci wariant pracy centrali to wariant pośredni. Najpierw jak po-

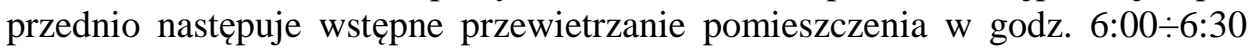
z wydajnością $150 \mathrm{~m}^{3} / \mathrm{h}$, następnie jednostka pracuje w godz. 8:00 $\div 10: 00$ i $12: 00 \div 14: 00 \mathrm{z}$ wydajnością $120 \mathrm{~m}^{3} / \mathrm{h}$.

\section{Zapotrzebowanie na energię}

W celu analizy wybranych wariantów najpierw obliczono zapotrzebowanie na energię do podgrzania powietrza wentylacyjnego oraz moc strat ciepła na podgrzanie tego powietrza. Wyniki zestawiono w Tabeli 1.Natomiast w Tabeli 2 podano liczbę godzin pracy instalacji w ciągu roku $\mathrm{z}$ uwzględnieniem podziału na poszczególne stopnie pracy wentylatora dla wybranych wariantów. Na Rys. 4. została przedstawiona moc strat ciepła na podgrzanie powietrza wentylacyjnego dla poszczególnych wariantów.

Tabela 1. Zapotrzebowanie na energię i moc na pokrycie strat ciepła na podgrzanie powietrza wentylacyjnego

Table 1. Energy requirement and maximum heating load for ventilation

\begin{tabular}{|c|c|c|c|}
\hline $\mathbf{N r}$ & $\begin{array}{c}\text { Liczba godzin pracy } \\
\text { instalacji ogrzew- } \\
\text { czej [h] }\end{array}$ & $\begin{array}{c}\text { Energia na podgrzanie } \\
\text { powietrza wentylacyjnego } \\
\text { [kWh] }\end{array}$ & $\begin{array}{c}\text { Maksymalna moc strat ciepła } \\
\text { na podgrzanie powietrza } \\
\text { wentylacyjnego } \\
\text { [kW] }\end{array}$ \\
\hline 1 & 2299 & 193,77 & 0,38113 \\
\hline 2 & 2419 & 196,25 & 0,38135 \\
\hline 3 & 2197 & 198,39 & 0,56113 \\
\hline
\end{tabular}

Tabela 2. Liczba godzin pracy instalacji ogrzewczej na pokrycie strat ciepła na wentylację w poszczególnych wariantach

Table 2. Number of heating hours for ventilation heat losses in selected cases

\begin{tabular}{|c|c|c|c|c|c|c|}
\cline { 2 - 7 } \multicolumn{1}{c|}{} & \multicolumn{2}{c|}{ Scenariusz 1 } & \multicolumn{2}{c|}{ Scenariusz 2 } & \multicolumn{2}{c|}{ Scenariusz 3 } \\
\hline $\begin{array}{c}\text { Stopień pra- } \\
\text { cy wentyla- } \\
\text { tora }\end{array}$ & $\begin{array}{c}\text { liczba go- } \\
\text { dzin pracy } \\
\text { w ciągu } \\
\text { roku }\end{array}$ & $\begin{array}{c}\text { \% liczba } \\
\text { godzin pra- } \\
\text { cy w ciągu } \\
\text { roku }\end{array}$ & $\begin{array}{c}\text { liczba go- } \\
\text { dzin pracy } \\
\text { w ciągu } \\
\text { roku }\end{array}$ & $\begin{array}{c}\text { \% liczba } \\
\text { godzin pra- } \\
\text { cy w ciągu } \\
\text { roku }\end{array}$ & $\begin{array}{c}\text { liczba go- } \\
\text { dzin pracy } \\
\text { w ciagu } \\
\text { roku }\end{array}$ & $\begin{array}{c}\text { \% liczba } \\
\text { godzin pra- } \\
\text { cy w ciągu } \\
\text { roku }\end{array}$ \\
\hline 0 & 6420 & 73 & 7460 & 85 & 7460 & 85 \\
\hline 1 & 2080 & 24 & 0 & 0 & 0 & 0 \\
\hline 2 & 0 & 0 & 1040 & 12 & 1040 & 12 \\
\hline 3 & 260 & 3 & 260 & 3 & 260 & 3 \\
\hline & 8760 & 100 & 8760 & 100 & 8760 & 100 \\
\hline
\end{tabular}




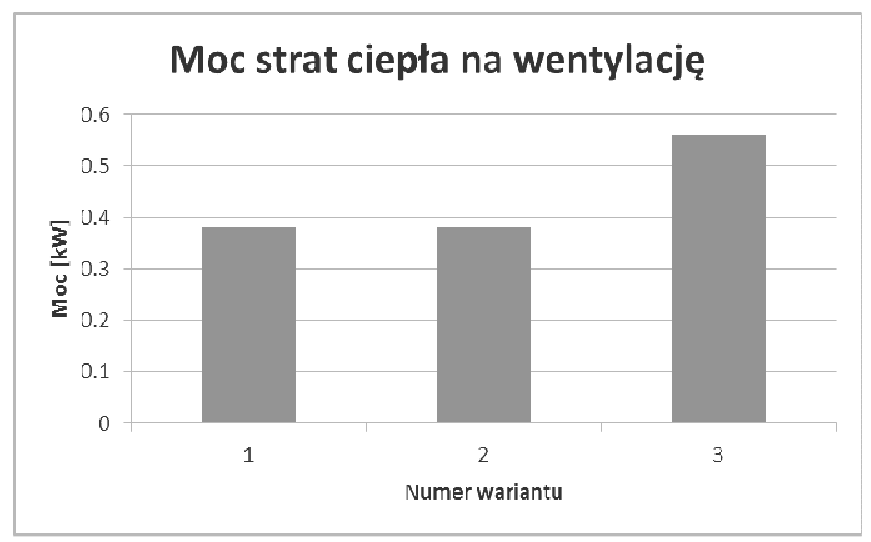

Rys. 4. Moc strat ciepła na wentylację

Fig. 4. Power heat loss for ventilation

Tabela 3. Obliczenia energii pomocniczej do napędu centrali

Table 3. Calculations auxiliary power to the drive unit

\begin{tabular}{|c|c|c|c|c|c|c|c|c|c|}
\hline \multirow[b]{3}{*}{$\begin{array}{c}\text { Tryb pracy } \\
\text { wentylatorów }\end{array}$} & \multicolumn{9}{|c|}{ Wariant pracy centrali } \\
\hline & \multicolumn{3}{|c|}{1} & \multicolumn{3}{|c|}{2} & \multicolumn{3}{|c|}{3} \\
\hline & $\begin{array}{c}\text { Czas } \\
\text { pracy } \\
\text { wentyl. } \\
{[\mathrm{h}]}\end{array}$ & $\begin{array}{c}\text { Pobór } \\
\text { mocy } \\
{[W]}\end{array}$ & $\begin{array}{c}\mathbf{E}_{\text {pom }} \\
{[\mathbf{k W h}]}\end{array}$ & $\begin{array}{c}\text { Czas } \\
\text { pracy } \\
\text { wentyl. } \\
{[\mathrm{h}]}\end{array}$ & $\begin{array}{c}\text { Pobór } \\
\text { mocy } \\
{[W]}\end{array}$ & $\begin{array}{c}\mathbf{E}_{\text {pom }} \\
{[\mathbf{k W h}]}\end{array}$ & $\begin{array}{c}\text { Czas } \\
\text { pracy } \\
\text { wentyl. } \\
\text { [h] }\end{array}$ & $\begin{array}{c}\text { Pobór } \\
\text { mocy } \\
{[W]}\end{array}$ & $\begin{array}{c}\mathbf{E}_{\text {pom }} \\
{[\mathbf{k W h}]}\end{array}$ \\
\hline 1 & 2080 & 22 & 45,76 & 0 & 22 & 0 & 0 & 22 & 0 \\
\hline 2 & 0 & 29 & 0 & 1040 & 29 & 30,16 & 1040 & 29 & 30,16 \\
\hline \multirow[t]{2}{*}{3} & 260 & 37 & 9,62 & 260 & 37 & 9,62 & 260 & 37 & 9,62 \\
\hline & \multicolumn{2}{|c|}{ Roczna $E_{\text {pom }}$} & 55,38 & \multicolumn{2}{|c|}{ Roczna Epom } & 39,78 & \multicolumn{2}{|c|}{ Roczna $E_{\text {pom }}$} & 39,78 \\
\hline
\end{tabular}

Następnie obliczono zapotrzebowanie na energię pomocniczą do napędu centrali, wyniki zestawiono w Tabeli 3 .

\section{Wnioski}

Analizując otrzymane wyniki najkorzystniejszym wariantem pod względem zapotrzebowania na energię do podgrzania powietrza wentylacyjnego oraz moc strat ciepła na podgrzanie tego powietrza otrzymano dla wariantu pierwszego, czyli ciągłej pracy centrali w godzinach 8:00-16:00, ze wstępnym półgodzinnym przewietrzaniem o godz. 6:00. Jednakże wariant ten okazał się najbardziej energochłonny pod względem zapotrzebowania na energię pomocniczą do napędu centrali wentylacyjnej. Natomiast przypadki drugi i trzeci posiadają takie samo zapotrzebowanie na energię pomocniczą, gdyż całkowity czas pracy na poszczególnych trybach w ciągu roku jest dla nich identyczny. Wariant 3 okazał się najbardziej energochłonny pod względem zapotrzebowania na energię do podgrza- 
nia powietrza wentylacyjnego oraz moc strat ciepła na podgrzanie tego powietrza. Ostatecznie rekomendowanym wariantem sterowania jest przypadek 2 czyli wentylacja interwałowa $\mathrm{z}$ krokiem godzinnym.

Niniejsza praca została sfinansowana ze środków Narodowego Centrum Badań i Rozwoju w ramach projektu pt.: „Promowanie zrównoważonego podejścia do efektywności energetycznej w budownictwie jako narzędzia ochrony klimatu w miastach Niemiec i Polski: opracowanie technologii fasady dla potrzeb budynków o zerowej emisji” (GPEE).

\section{Literatura}

[1] J. Sowa, A. Karaś, Whole year simulation of natural and hybrid ventilation performance and estimation indoor air quality for modernized school building, CLIMA 2007, WellBeing Indoors, Helsinki 2007.

[2] M. K. Kim, L. Baldini, Energy analysis of a decentralized ventilation system compared with centralized ventilation systems in European climates: Based on review of analyses, Energy and Buildings, Volume 111, 1 January 2016, Pages 424-433.

[3] D. Heim, D. Knera, M. Szymkowiak Możliwości zastosowania lokalnej wentylacji mechanicznej w obiektach szkolnych, XIII Ogólnopolska Konferencja "Problemy jakości powietrza wewnętrznego w Polsce”, 2015.

[4] www.gpee.net (data odsłony: 01.06.2016).

\section{ENERGY CONSUPTION OF LOCAL VENTILATION UNIT UNDER SELECTED CONTROL STRATEGIES}

\section{S u m m a r y}

The energy efficiency of local ventilation under different conditions are presented in the paper. The final and auxiliary energy were compared for three types of system controlling under office requirements of indoor air quality. In the final conclusions the recommended control strategy should use a interrupted algorithm with one hour of working mode (doubled air changes) and one hour of switching off.

Keywords: ventilation, control, office building, energy efficiency, air quality comfort

Przestano do redakcji: 04.01.2017 r.

Przyjęto do druku: 31.03.2017 r. 